\title{
On Freedom, Being and Transcendence: The Quest for Relevance in Higher Education
}

\section{CATARINA ANTUNES GOMES}

Social Sciences and Humanities Laboratory, Angolan Catholic University, Angola Centre of Social Studies, University of Coimbra, Portugal

In spite of an extreme diversity in terms of institutional designs, political environment and economic predicaments, the global landscape of higher education systems nowadays faces common trends that raise a number of perplexities and reframe the idea and the practice of the university. Those same trends compel us to analyse the university's contemporary challenges and conundrums, especially in terms of its social function and the core issue of its existence: critical thinking and intellectual freedom. Thus, central to this endeavour is questioning what critical thinking and intellectual freedom are, as well as what both imply in terms of educational practices and knowledge production. Quite beyond their market-oriented usefulness, the exercise of critical thinking and intellectual freedom might be best understood as the foundational condition for avoiding coercive normalisation, that is, the tools through which individuals and communities can sustain democratic control over institutions and exercise critical and conscious choices around identity matters and what futures to build. In this sense it is argued that critical thinking - itself an experience of freedom - should be translated into forms of transcendence through which historical limits imposed on individuals and communities can be challenged. The conundrum is to assess, in present-day conditions, how the university can pursue and defend critical thinking and intellectual freedom.

\section{Keywords}

critical thinking, intellectual freedom, role of education, political conformity, thoughtlessness

\section{Introduction}

the uncompromisingly critical thinker, who neither superscribes his conscience nor permits himself to be terrorized into action, is in truth the one who never give up...thinking is not the spiritual reproduction of what exists. As long as thinking is not interrupted it has a firm grasp upon possibility. Its insatiable quality, the resistance against petty satiety, rejects the foolish wisdom of resignation. ${ }^{1}$

1 Theodor Adorno cited in Edward W. Said, 'On Lost Causes' in Edward W. Said, Reflections on Exile and Other Literary and Cultural Essays (London: Granta Publications, 2012), 553. 
In spite of an extreme diversity in terms of institutional designs, political environment and economic predicaments, the global landscape of higher education systems today faces common trends that raise a number of perplexities while reframing the idea and the practice of the university. Those same trends compel us to analyse the university's contemporary challenges, especially regarding its social function and the core nature of its existence: critical thinking and intellectual freedom. On the one hand, any inquiry of current conundrums needs to take these forces into consideration in a historical perspective. On the other hand, all critical projection of any desirable future needs a profound meditation on the university's roles and its social and historical responsibilities. And this meditation needs to be socially and historically grounded as well as hermeneutically articulated in order to answer specific demands while remaining open to other experiences, loci and positionings in the pursuit of a cosmopolitan citizenry.

The trends that will be discussed in this paper are the result of forty years of what has been widely called neoliberal hegemony. ${ }^{2}$ These trends profoundly affect our ability to engage in critical thinking, to secure intellectual freedom and to question power structures. For example, while there has been a growing interest in epistemic decolonisation, the ability and the degree of involvement in those debates vary widely according to different institutional and political contexts. Technically sophisticated, these trends have been reshaping even the juridical persona of universities. In this context, a significant process of 'depoliticising politics' emerges, whereby politics is reduced to a procedural technocracy that feeds a sense of inescapability, of the necessary course of history and of the absolute lack of alternatives.

\section{Critical voices}

The worst insult my mother could think of was to call someone a technocrat. ${ }^{3}$

A number of critics from different traditions and loci of enunciation have pointed out not only the many fallacies in current reforms of higher education systems, but also their profoundly problematic scientific, political and ethical effects. For instance, Sabelo Ndlovu-Gatsheni discusses global neoliberal imperialism and its effects on power structures and knowledge coloniality. Through a deep critique of 'consultancy cultures', 'commercialized institutions of higher education' and the 'devaluation of humanities and social sciences', he stresses 'the colonization of African imagination

2 Being a central element of hegemonic globalisation, the neoliberal orthodoxy emerged historically from the transformation of governance as a problem of legitimacy to governance as a problem of governamentability. In the 1970s, the challenge was mainly one of reinforcing inclusion and participation and, therefore, of strengthening democratic life as well as the idea of the social contract. But the following decades redefined this democratic legitimacy quest into a crisis of governamentability, which demanded the downsizing of social aspirations directed to the state. Under the Washington Consensus, this redefinition originated a new regime guided by the principles of 'minimal state', liberalisation, privatisation and civil society participation (identified with social actors and also with markets and described in governance models). This model has been disseminated worldwide as the hegemonic 'development' narrative. See N. Chomsky, Profit over People: Neoliberalism and Global Order (New York: Seven Stories Press, 1999); B.S. Santos, ed., Cognitive Justice in a Global World: Prudent Knowledge for a Decent Life (Lanham, MD: Lexington, 2007).

Catarina Gomes, 'The Liers' Book or Essays on Remembrance', unpublished manuscript. 
and displacement of African knowledges' as well as the permanent shaping of 'global values. ${ }^{4}$ Focusing on different contexts, namely Europe and Asia, Jon Nixon gives a similar account of these trends. ${ }^{5}$ Concerning higher education institutional models, he writes of the erosion of an ethics of public service and the consecration of an increasingly managerial, administrative and efficiency-oriented model of organisation. Nixon also draws attention to increasing levels of precariousness in academic and research careers, creating a sort of new highly qualified lumpenproletariat. The perversities of sanitised forms of competition within and between institutions, which produce novel dynamics of marginalisation and the blunt exclusion of people and institutions, are another serious cause of concern. In accordance with Ndlovu-Gatsheni, Nixon criticises the ideological trap of presenting these policies as unavoidable. JeanMarc Ela develops a strong critique of the World Bank recommendations in terms of higher education, emphasising their implications for an African university increasingly submitted to markets' whims. ${ }^{6}$ In a foundational essay in his Secure the Base, Ngũgĩ wa Thiongo explains how current forms of capitalist globalisation are being intensified and contributing to the emergence of a capitalist fundamentalism coupled with the belief that there is no alternative. ${ }^{7}$ Such naturalisation becomes a force of coercive acceptance of a present and a future where human agency, freedom and aspirations count for little.

\section{Tales on education...}

This is science, not politics! $!^{8}$

In terms of the depoliticisation of knowledge, I wish first to emphasise the ways in which insidious forms of Eurocentric and positivist imagination make themselves present in our academic and intellectual practice through the revival of values of objectivity, neutrality and efficiency, amongst others, as criteria of validity. The longstanding debate between distinct models of objectivity developed under the classical hierarchy of knowledge fields still has the capacity to present itself in academia and also in social expectations. These expectations have been naturalised through the dominance of a culture of the fact, of the datum. For Ela, the imperialistic nature of such culture is at the core of the current rationality crisis - one which is accountable for the dissemination of forms of neo-obscurantism. ${ }^{9}$ The prevailing preference for numerical and technical translation of realities signals a high level of anxiety manifested in the need to tame chance. And, ironically (or not so much), this is a preference that is being reinforced in a global context of increasing vulnerability and unpredictability.

\footnotetext{
Sabelo J. Ndlovu-Gatsheni, Coloniality of Power in Postcolonial Africa: Myths of Decolonization (Dakar: Codesria, 2013), xi. Jon Nixon, Towards the Virtuous University: The Moral Bases of Academic Practice (New York: Routledge, 2008).

Jean-Marc Ela, As culturas africanas no âmbito da racionalidade científica (Luanda: Mulemba, 2016).

Ngũgĩ wa Thiong'o, Secure the Base: Making Africa Visible in the Globe (London: Seagull Books, 2016).

Gomes, 'The Liers' Book'.

Jean-Marc Ela, Investigação científica e crise da racionalidade (Luanda: Mulemba, 2016).
} 
But perhaps the main challenge offered in critiques of depoliticised knowledge is to draw attention to a neglect of epistemological vigilance and to the social, cultural and historical nature of any knowledge proposition. This neglect reinforces the impression that, for instance, science is monocultural. It reinforces blindness towards the political and ethical responsibilities of knowledge production, as well as its cultural and historical nature. Finally, it neutralises demands for the recognition of epistemological diversity and/or for epistemic decolonisation as absurdities or eccentricities.

One of the best examples of this is the contemporary dissemination of the Problem Based Learning (PBL) methodology. ${ }^{10}$ Between 2008 and 2011, I was asked to teach a weekly seminar of health anthropology to undergraduate students of biomedical and pharmaceutical sciences at a Portuguese university according to the PBL methodology. Enforced by the institution, this learning methodology obeys what is called a 'minimum guidance principle', which states that students are the ones guiding their own learning process and selecting and defining their own learning objectives. In this context, a tutor replaces the teacher. Students are responsible for their own research and for selecting relevant information. Naturally this was done by mobilising their own worldview and presuppositions. The overall result was the intensification of students' adherence to an evidence-based discourse that did not even question what evidence is. In fact, with PBL, institutional colonial expectations became even more evident. From the institution's perspective, anthropology was conceptualised as a discipline to convert alterity into modernity, symbolised by science. A crude distinction was then celebrated between science as real and objective knowledge and other systems of knowledge described as belief systems and thus subjective, cultural and invalid. The result, aggravated by a complete absence of any consideration for historical processes, was the production of monothetic comparisons, to use Arjun Appadurai's concept, ${ }^{11}$ and the stereotypification of different realities. This, in turn, served to confirm the validity of students' worldviews.

While alerting his readers to the way science can operate as an ideology that undermines intellectual independence, Paul Feyerabend criticised this model of scientific education long ago in the following manner:

[I]t simplifies 'science' by simplifying its participants: first, a domain of research is defined. The domain is separated from the rest of history (physics, for example, is separated from metaphysics and theology) and given a 'logic' of its own. A thorough training in such 'logic' then conditions

10 As a learning methodology, PBL was initially formulated in the 1960s/1970s at the Medicine Faculty of the University of McMaster in Canada. The model was rapidly disseminated in many biomedical faculties and has been adopted worldwide in many other fields of knowledge, such as engineering, law, education and social sciences. The experience ended up by allowing the production of an ethnographically based account of PBL as a manifestation of a problem of knowledge coloniality and its geopolitics. See Catarina A. Gomes, 'Evolutionism Is Dead! Long Live Evolutionism. New Paths of the Coloniality of Knowledge and Reason', TERRA-HN, http://www.reseau-terra.eu/article1222.html (accessed 5 October 2017).

11 Arjun Appadurai, Modernity at Large: Cultural Dimensions of Globalization (Minneapolis, MN: University of Minnesota Press, 1996). 
those working in the domain; it makes their actions more uniform and it freezes large parts of the historical process as well. Stable 'facts' arise and persevere despite the vicissitudes of history. ${ }^{12}$

Overall, it was clear that an uncritical use of PBL would easily amount to the reproduction of Eurocentric modern and positivist imaginaries that resonated with neo-evolutionist theses and the full force of the old colonial library. In students' readings, cultural diversity was attributed to the lack of scientific knowledge; scientific education became the foundation of true development manifested in the abandonment of local belief systems. Claude Lévi-Strauss' condemnation comes to mind of how, for ethnocentrism, cultural diversity is a scandal. ${ }^{13}$

Why has PBL gained such popularity? There is an important connection between the reproduction of this imaginary and neoliberal policies in higher education institutions. Institutions are requested to focus on what works and on training, reducing the true value of knowledge and reflexivity into market knowledge. The recognition of this connection motivated Henry Giroux to classify neoliberal educational policies as the 'pedagogy of market-driven illiteracy'14 - that is, as Boaventura de Sousa Santos has argued, the creation of endless illiteracy while creating endless knowledge. ${ }^{15}$ In this sense, the university not only suffers from these external pressures or global trends; it becomes a privileged locus for the production and naturalisation of a worldview marked by what Thiongo named as capitalist fundamentalism.

Naturalisation always produces legitimation. But a special sort of legitimation: one that doesn't come from effort, transgression, conscious choice, but one that comes from sedimentation and an apparent lack of choice. Bad faith, Jean-Paul Sartre would say, has invaded and killed imagination. ${ }^{16}$ This idea of absence - the absence of choice or alternative - is a disenchanted one. One perpetuates and intensifies the present. One renounces agency and responsibility. One complies with consecrated methodologies and epistemic principles for the sake of a desired object or a needed fact.

And here the classic Foucauldian notion of docility emerges once again with all its glare in the form of a depoliticised being. New forms of docility come into being and one of its instruments par excellence is education. Education has always played a crucial role in distributing validated knowledge and discrediting other forms of knowledge, in legitimising social roles and identities, frequently reproducing age-old axes of discrimination such as gender and race, as well as new axes such as ageism and technological illiteracy.

12 Paul K. Feyerabend, Against Method: Outline of an Anarchistic Theory of Knowledge (London: Verso, 1993), 11 (emphasis in the original).

13 Claude Lévi-Strauss, Structural Anthropology, translated by Claire Jacobson and Brooke Grundfest Schoepf (New York: Basic Books, 1963).

14 Muhammad H. Bhojani, 'Neoliberalism's War on Higher Education: Book Review', Journal of Education and Educational Development, 3(1) (2016), 135.

15 Boaventura de Sousa Santos, 'The University at a Crossroads', Human Architecture: Journal of the Sociology of Self-Knowledge, 10(1) (Winter 2012), 7-16.

16 Jean-Paul Sartre, Being and Nothingness: A Phenomenological Essay on Ontology, translated by Hazel Estella Barnes (New York: Washington Square Press, 1992). 
One could here recover the work of Pierre Bourdieu, Edgar Morin or Paulo Freire. Bourdieu's analysis represented a valuable rupture with triumphalist narratives about modernity's progress in the field of education. ${ }^{17}$ By unveiling how educational systems contribute to the reproduction of social inequalities, Bourdieu provided a powerful critique of the naïve linear correlation between mass education and the equality/democratisation axis. Morin argued for an ecosociology of knowledge - one that would build up awareness about the dynamic of mutual constitution between science and culture. ${ }^{18}$ Since it is not produced in a void, knowledge simultaneously is produced and produces culture and, in that gesture, allows certain horizons of possibility for human existence while blocking others. Freire developed his critical thinking anchored on the idea that education should serve citizenship and emancipation, having therefore a clear responsibility in the critique of power structures of inequality. ${ }^{19}$ The relevance of education as a technique of conversion aimed at the production of normalised subjectivities can be even more fully appreciated in historical experiences of colonial domination. For instance, Thiongo argues that the most important area of colonial domination

was the mental universe of the colonized, the control, through culture, of how people perceived themselves and their relationship to the world. Economic and political control can never be complete or effective without mental control. To control a people's culture is to control their tools of selfdefinition in relationship to others. ${ }^{20}$

Indeed, one could look at history and detect the uses of education to forge identities, common senses, imaginations and horizons of possibility. I can remember my mother who was taught at school 'the economics of domestic life'. I can remember my father who was taught at a Catholic seminar the need to evangelise. And I can remember their disenchantment and their neurotic quest for themselves. I can remember my aunts' elementary school manuals and I can remember the pictures of primitive peoples and the hymns to celebrate Portugality. What and how are we being taught to think?

Later I learned how Portuguese colonial rule invested in education for indigenous people from 1961 onwards, at the precise moment when struggles for liberation in Mozambique and Angola broke out. In Angola, this policy was officially baptised as 'The battle for education'. Again Michel Foucault. The notions of disciplinary power and biopolitics are latent spectrums. And Valentin-Yves Mudimbe. The massive practice of conversion. Reading documents from the countersubversion cabinet of the Portuguese army in Angola, one learns, for instance, how important schools

\footnotetext{
17 Pierre Bourdieu and Jean-Claude Passeron, Reproduction in Education, Society and Culture, translated by Richard Nice (London: Sage, 1990).

8 Edgar Morin, On Complexity (Cresskill, NJ: Hampton Press, 2008).

19 Paulo Freire, The Politics of Education: Culture, Power and Liberation (Westport, CT: Greenwood Publishing Group, 1985).

20 Ngũgĩ wa Thiongo, Decolonizing the Mind: The Politics of Language in African Literature (Nairobi: East African Educational Publishers, 1986), 16.
} 
were to co-opt populations, to mystify the adversary and to alienate people in order to embrace an ideal of Portugality that always eluded them. For their part, liberation movements, such as MPLA (Movimento Popular de Libertação de Angola), emphasised strongly the importance of education and created the Centres for Revolutionary Instruction (Centros de Instrução Revolucionária). Education was clearly political. It was seen as being crucial to overcome the alienation produced precisely through education. After independence and with the adoption of Marxism-Leninism, MPLA, now a vanguard party, continued to use education as an instrument to give life to a New Man, that is, a new subjectivity freed from colonialism, liberalism and tribalism. However, soon this new subjectivity meant the enforcement of a disciplinary regime where critical thinking and intellectual freedom were discarded as bourgeois and counterrevolutionary behaviour. A well-known tale.

Within the global context of neoliberal hegemony, rapid technological innovation, the risks of obsolescence, the demands for competitiveness, the minimal state, the individualisation of risks and markets' demands for worker flexibility and adaptability, globalisation and economic growth are common arguments demanding a global reorientation of educational policies.

This meta-narrative has been deployed in two interrelated dimensions. The first is a redescription of the purpose of education and has been at the centre of political discourses in the global North. According to that redescription, educational policies should be attributed with two fundamental roles: to assure employability and, thus, economic growth; and to assure that, through education, individuals have their own tools and resources to individually manage their own lives and to deal with an increasing social vulnerability.

Employability has been internationally defined as the individual capacity to be attractive to the labour market, whereas the second role attributed to education has been subsumed under the label of citizenship. A conceptual alliance emerged then: the alliance between citizenship and employability, where the latter becomes an essential element of the former. That is, by assuring social integration, employability becomes the privileged road to citizenship. Indeed, citizenship is increasingly interpreted not necessarily as the result of recognition and belonging, but as individuals' capacity to be accountable for their own biographical trajectory at the precise moment when their social and political rights, supports and defences are suffering increasing erosion. The classic idea of a 'social contract' is now made even more dependent upon the individual's ability to integrate into the labour market. ${ }^{21}$

The second dimension concerns development issues. Together with the first dimension, it has been used primarily to address the global South. Basically, it states that a knowledge economy is crucial to promote development and the ability of countries

21 This reconfiguration relates to the emergence of what Santos designates as social fascism. In the author's perspective, social fascism does not mean the return of historical fascist experiences. It means the emergence of social relations that produce inequalities so accentuated that the safeguards of democracy are of little worth. And given the primacy of the market's needs, an array of new forms of exclusion come into being. In what concerns the labour market more specifically, social fascism becomes characterised by two main logics: firstly, postcontractualism, which is the process by which groups included until now in the social contract are excluded from it; secondly, precontractualism as the blocking of access to citizenship to groups previously considered potential candidates for citizenship. See Santos, 'The University at a Crossroads'. 
to face international competition. In this sense, the World Bank, for instance, has argued for the university's role in economic development in a depoliticised language that does not allow for questioning of what economic development might be, while, at the same time, it proposes centring attention on disciplines that can directly contribute to the markets' vitality. ${ }^{22}$

In both dimensions of this meta-narrative, the prevailing models of education in our capitalist world system can be linked to the active production of new forms of docility, in spite of the celebration of 'individuality', 'creativity', 'autonomy' and 'innovation', to mention just the central values of our contemporary prevailing ethos. Hence, notions such as 'citizenship', 'employability' and 'development' might be critically deconstructed as (bio)political strategies that aim at the dissemination of new sociopolitical profiles of subjectivity able to serve the markets' needs.

New forms of institutionalising hierarchies between knowledge's branches, such as science, technology, engineering and mathematics, on the one hand, and humanities on the other, became even more widely adopted. Life-long learning policies were meant to become a common practice to actualise professional profiles and avoid people's obsolescence. Markets' needs became the fundamental criteria to define curricula, to fund research, to educate people. Universities are invited to adopt models of governance that can easily be hijacked by economic interests when defining educational priorities and policies. Investment in research is dependent on the ability to produce 'real innovation' in terms of scientific, technological or industrial advancement. And when dealing with social realms, such as rights, citizenship, inclusion and so forth, funding programmes promote a similar outlook. Social sciences and humanities tend to become subjugated by a new linguistic apparatus - one that includes new concepts such as 'finding,' 'social innovation' or 'entrepreneurship', and normalised discourses on the importance, for instance, of 'productive ageing' or of folkloric assessments on multiculturalism, amongst others. Another well-known tale.

Is education being depoliticised in this context? Indeed, if we consider its instrumentalist reduction. The lessons learned with Bourdieu, Morin and Freire, amongst many others, seem to be forgotten. Where is the systematic critique of education as an axis of inequality when our educational systems are increasingly dualised and subjected to rankings that influence funding and investment? Where is Morin's awareness, according to which knowledge is culturally produced, its productions foreclosing certain possibilities? How are policies addressing the illusion of emancipation criticised by Freire? A depoliticised education is always politically produced.

The links between an epistemic order and social and ontological possibilities should not be neglected. It was by no accident that Foucault traced the relationship between a will to knowledge, a will to truth and a will to power. Hence, likewise, one can trace a relationship between, on the one hand, a depoliticised education accompanied by an erosion of humanities, and, on the other, the demise of citizenship and democracy. For Martha Nussbaum, humanities cultivate the essential qualities 
for democratic life; these include critical and independent thinking and action, the refusal of blind obedience and autocratic powers and the ability to engage in empathetic forms of imagination where the recognition of shared vulnerability paves the way for a cosmopolitan citizenry. ${ }^{23}$ On the other hand, because of its practices of reflecting upon the complex entanglements between science, society, politics and so forth, humanities has the potential to enlarge the social base for knowledge production and decision-making, contributing thereby to the democratisation of these processes. $^{24}$

\section{Is there a value in humanities? A critique of humanities' capture}

From where should I expect the word that will announce me? ${ }^{25}$

It is commonly stated that humanities and social sciences are currently under attack within this global political economy. Despite their differences and the difficulty in (or lack of relevance in) establishing clear-cut frontiers between these fields, both are questioned from the point of view of their usefulness and productivity. ${ }^{26}$

Usually this questioning produces a twofold effect. On the one hand, it resituates humanities in a peculiar position: it has to justify itself. By demanding an intelligible answer from the field (that is, one that can be aptly apprehended by contemporary codes), the appeal is indeed questioning the usefulness of an existence. The meaning of existence is therefore dislocated from the facticity and historicity of its own being to its explicit practicality, function or purpose. Another side effect consists in the adoption of a defensive positioning. This reaction manifests in two main forms: the attempt to demonstrate the economic value of the field, thus subscribing to the contemporary hegemonic ethos; and the attempt to emphasise how it is fundamental for issues such as education, values and heritage. ${ }^{27}$

In current political and academic discourses defending humanities, it is common to find the argument that the field has a significant social value, as well as an economic one. Humanities' overall benefits for society would be easily listed: tolerance, citizenship, social cohesion, decision-making, critical thinking, progress, etc. This generic description of humanities' benefits does not answer to foundational interrogations: Who is producing knowledge? With what? For whom? And it seems to be closely linked to what is articulated as the economic value of the field. Humanities' 'economic value' has been related not only to the direct economic benefits associated

\footnotetext{
Martha Nussbaum, Not for Profit: Why Democracy Needs Humanities (Princeton, NJ: Princeton University Press, 2010).

B. Latour, Cogitamos: Six letters sur les humanités scientifiques (Paris: La Découverte, 2010).

Gomes, 'The Liers' Book'.

Due to space constraints, from now on I use the term 'humanities' to refer to both.

In order to develop a critique of these two main positionings, let us reflect upon a ground-breaking work that illustrates how humanities is being disputed nowadays. Entitled Humanities World Report 2015, the work was the result of extensive and worldwide research conducted by Poul Holm, Arne Jarrick and Dominic Scott. Overall, the report aims to assess the worldwide state of humanities through the voices of scholars inscribed in distinct scholarship traditions and institutional settings. One of the key issues debated was how scholars and humanists around the world articulate the field's value. This naturally raised multiple answers that the authors tried to aggregate in an intelligible taxonomy of values: intrinsic value; social value; cultural heritage; economic value; contributions to other disciplines; innovation; personal and spiritual development; and aesthetic appreciation. See P. Holm, A. Jarick and D. Scott, Humanities World Report 2015 (London: Palgrave Macmillan, 2015).
} 
with the main activities of the field, such as publishing, education and professional training, but also to the outcomes and empirical application of humanities' research on topics such as rights, welfare, poverty, exclusion, income distribution, health, justice, employment, environment, etc., and their contributions in terms of policymaking. Briefly, what is being communicated is how humanities can contribute to another well-known policy motto: social cohesion.

Now, in the midst of other possible questionings, let us focus on one crucial problem with this approach. Considering once again the above description, one can think about humanities' social value as that which makes possible and reinforces the collective. But who is this collective? These discourses on social cohesion are being spoken by whom? Who are they supposed to address? And couldn't we ask: social cohesion concerning what or around what? Does this social cohesion imply the adherence to a dominant status quo or worldview? Or, on the contrary, is it referring to an enlargement of social bounds through the multiplication of modes of recognition and the proliferation of social presences and participations? Is the value of humanities to be measured only in terms of its usefulness to contemporary orthodox policymaking agendas?

From a related point of view, the social value idea translates the idea of engaged knowledge. The classical image of the ivory tower of knowledge is now replaced by an active involvement in human affairs. Albeit sometimes presented as a novelty, given the historical consecration of values concerning objectivity and neutrality, that active involvement has always been a classical disposition of the field. Just think about how any philosophical tradition addresses the idea of a 'good life', for example. But given the global context described previously, it becomes crucial to understand how this new active involvement relates to issues of independence and responsibility. How to qualify this active involvement? Engagement in what? Is it really independent?

The argument according to which humanities contribute to a culture of innovation is especially eloquent in this respect. This reading is susceptible to two main interpretations. Both dispute the sociolinguistic value-laden idea of innovation. On the one hand, we find an interpretation which is closely linked with current political and economic usages of the concept. ${ }^{28}$ In this perspective, humanities can present an innovative potential when its products or findings are integrated into market circuits, thus promoting a knowledge society in our contemporary global economy. On the other hand, if we detach the concept of innovation from these usages, we realise that its fundamental meaning is to effect a change. And if we keep this in mind and acknowledge humanities' role in producing realities and horizons of possibility, namely through critical thinking (in literature, arts, philosophy, cultural studies, history and so forth), we can easily identify instances where humanities represented groundbreaking innovations. One might also add that humanities' role in understanding and critically challenging social realities, practices and beliefs constitutes a central tenet model and its usages shows how its particular conceptualisation of knowledge corresponds to its commodification in a global competitive economy. 
for the renewal and actualisation of social life and human existence in multiple domains. One could stress, for example, humanities' contribution to other disciplines, including hard natural sciences. The world's complexity can only be grasped through the recovery of interdisciplinary and intercultural thinking processes. It should also be strongly emphasised that the subject of contributing to other disciplines discloses the importance of humanities' epistemological work, namely critically reassessing theories and knowledge production's presuppositions through an ethically guided epistemological vigilance. And this has been fundamental for the development of, for instance, postcolonial analysis and the critique of the colonial library. ${ }^{29}$

The expectations that social sciences and humanist research contribute to policy decisions are often put in terms of 'findings', 'evidences', 'models' or 'innovations'. And here lies an additional responsibility for humanities. Indeed, any critique of social and political expectations on academic and activist research has to raise a particular awareness: that numbers and statistics and even models of social intervention constitute manners of communicating belief systems that currently inform the public and the public policy in fundamental ways. Even when included in the exercise of 'diagnosing social problems', humanities' contribution tends to be profoundly instrumentalised. That means that the relationship between expertise and public policy does not necessarily mean that the latter will be the outcome of more inclusive and participatory processes of knowledge production and decision-making. Nor does it mean necessarily (or easily) that the production of new knowledge is to be developed through an epistemological and historical questioning of established premises.

Consider mainstream international cooperation for development policies. One basic assumption is that knowledge production in international cooperation programmes should not explicitly engage in politics. This supposed neutrality unveils itself as a sort of coercion on two different levels: at the local level, because such a neutrality does not defy explicitly installed power structures; at the global level, because any knowledge production needs funding, which depends basically on donors' policies and agendas. From this perspective, for instance, research on poverty tends to be divorced from critical discussions addressing structures of inequality as structures of violence or from critical assessments of regimes of citizenship. That would mean politicisation. Although posed as a social problem, poverty is thus to be resolved through technical interventions mainly based on the same presuppositions that are, at least partially, responsible for its emergence and proliferation. In this sense, a selfreferential knowledge production may easily foster dogmas' self-reproduction.

\section{Humanities for transcendence: The problem of identity}

My house, now I see, was built to remain empty, because its doors cannot open. ${ }^{30}$ 
Another value that is being currently articulated informs us about the importance of humanities for cultural heritage issues. In this perspective, humanities is seen to contribute to the understanding and preservation of cultural heritages. This first-order observation corresponds to certain mainstream readings of humanities which are closely linked to the emergence of nationalisms. But this immediately raises a concern: that of giving legitimacy to essentialists' readings of cultural universes. And this concern leads us directly to the core of intellectual activity: criticism and freedom.

The concern about the use of humanities to justify essentialist and therefore exclusionary identity politics can only be surpassed when cultural heritages or universes are understood critically. A second-order observation necessarily imposes itself. This is especially important for contexts such as postcolonial Angola, amongst many other possible examples worldwide, where the debate about 'identity politics', anchored on essentialist readings of angolanidade (being Angolan), is also present in everyday discourses, thus determining who has the right to belong and speak. The historical relationship between forms of state nationalism and essentialism and normative outlooks on identity should not be forgotten.

A second-order observation needs then to address explicitly this kind of demagogy that instrumentalises humanities to convey conservationist stances on identity politics. It is explicitly directed towards those aspects of human experience that produce violence and oppression or a miniaturisation of the human spirit, as Amartya Sen explains. ${ }^{31}$ Hence, humanities can only be thought as belonging to a secondorder observation practice. If this is the case, then one should acknowledge humanities' role in producing human realities and experiences, by thematising them critically and by opening up horizons of possibility. Of course, this raises the issues of responsibility and independence, as mentioned earlier. Hence, although there seems to be a requalification of humanities through the notion of engaged knowledge or through a new appraisal of cultural heritages, it might be useful to distinguish between a first-order use leading to attestation of normative readings and a secondorder observation or practice, intrinsically critical and open-ended.

\section{Humanities for transcendence: The problem of freedom}

Freedom is not reverential. ${ }^{32}$

It is never easy to define what academic and intellectual freedom is; its meanings, implications and challenges differ historically and also according to specific contexts. Hence, while it remains crucial to reflect theoretically upon intellectual freedom, it is also indispensable to consider critically what it means for each milieu.

31 Amartya Sen, Development as Freedom (Oxford: Oxford University Press, 1999).

32 Gomes, 'The Liers' Book'. 
One interesting way to try to think about this is related to a shared conundrum: either the university becomes a site of conversations and debates about societal challenges, running the risk of becoming co-opted by powerful agendas; or it dedicates itself to pursuing forms of pure knowledge with no relation to those demands and pressures, hence running the risk of becoming a solipsist institutional arrangement.

Both positions in this dilemma translate, in fact, into different conceptualisations of the social role of universities. The first posits the university as an instrument of something. While taking the form of an instrument, the university is supposed to execute, materialise and produce goals or aims previously defined. In this perspective, independence of thought does not need to be at the core of what a university is supposed to be. The second positioning, on the other hand, posits independence as a condition for the university's existence. The problem is the temptation to describe independence as requiring a necessarily solipsist attitude toward social realities in order to engage in the classic ideal of achieving truth and pure knowledge no matter what.

Historically, the two positions have been related to each other as antitheses. However, upon further reflection, one might see both positionings as a result of a determined gesture - the gesture of confusing context-driven dynamics with perennial structures, that is, crystallising context-dependent aspirations into dogmatic assertions. If one adopts this deconstructive analytical possibility, one sees the shortcomings of both.

In the first position, excessive instrumentalisation and structural co-option of knowledge is a denial of independence and, consequently, of critical thought. Even worse: in those circumstances, the university is readily transformed into an important source of legitimacy for existing power structures. Its productions convey certain senses of being, reality and necessity that condition the very fabric of reality as it is lived. Knowledge is not knowledge of a being, a reality, an experience in a given place, time and position; it is a simulacrum whose purpose is to create a determined reality. Just think for a moment about the history of anthropology. Or the history of once-consecrated concepts, such as race. Or today's mythologies, such as the balance of free markets, structural arrangements on the economy or the receipts for development. In all those instances, what one finds is a massive production of legitimising narratives in spite of knowledge and critical thought.

In the second position, and at first sight, the issue of independence does not seem to be at risk. But the related issues of purpose and responsibility clearly are. The mythology of pure knowledge has always been immensely seductive. It shields us from responsibility in questioning our premises and in facing the consequences of our activity. The Manhattan Project was a scientific endeavour, politically driven, with undeniably catastrophic consequences worldwide. Adolf Eichmann argued that he was following orders while efficiently organising a superb industry of death - one that was rehearsed in Namibia in the early twentieth century in the name of science and civilisation. The wounds of Congo and the Great Lakes live to this day as the aftermath of scientific and civilising missions. The magnitude of consequences is such that the supposed independence of knowledge cannot remain immune to critique. 
Moreover, it is the consequences that unveil the social and political embodiment of any knowledge. ${ }^{33}$

\section{Angola's experience}

Xê menino, não fala política! ${ }^{34}$

Let us consider a very brief summary of Angola's contemporary history. After independence, in 1975, and the downfall of the Bicesse peace accords, MPLA gained control over the state apparatus and the government in the background of a raging civil war. When in power, it installed a uniparty Marxist political system. From this perspective, independence was marked by two factors: a violent and long civil war and an authoritarian regime of centralised power characterised by (neo)patrimonial rule. Both have had a strong influence on what may be called 'local political culture'.

In the mid-1980s, this power system faced a crisis, mainly due to the decline of income from the oil industry. Alongside this economic crisis, which produced large-scale famine and aggravated the civil war's consequences, the international community pressured the regime to embrace economic and political liberalisation. This resulted in reforms to adopt an open market economy and multiparty politics. In 1992, the first general elections were organised. A national government of unity and reconciliation formed by the three former liberation movements was established. But in that same year the war was resumed and new peace negotiations were unsuccessful in stopping the conflict. This led to one of the longest humanitarian disasters on the continent.

The end of the civil war was achieved in 2002 and it was not the fruit of peace negotiations. It had a military resolution. ${ }^{35}$ In 2008 , the second general elections were organised and the MPLA won with $81.76 \%$ of the votes. This overwhelming victory allowed for a constitutional revision in 2010 that consecrated a presidential regime marked by a strong concentration of powers. ${ }^{36}$

Nowadays, another significant economic and social crisis is affecting the country due to the recent downfall in oil prices. This new crisis is revealing how frail development has been since the end of civil war. Economic development - basically anchored on the oil industry - has not translated into social and human development. For instance, investment in education and health has been constantly under the average of the public investment in sub-Saharan Africa, which is above 6\% of the GDP.

It is also interesting to understand how both positionings are deployed as arguments of the same meta-narrative. The first one (the necessary engagement of the university) is useful in order to prove the necessity of the institution. The second argument (regarding independence) is also useful to shield the institution from political questionings.

34 Popular Angolan saying: 'Child! Don't speak politics!'

35 In April 2002, MPLA troops succeeded in defeating their direct rival, Unita (União Nacional para a Independência Total de Angola).

36 While writing this paper, the 2012 elections took place and again MPLA won with $71.84 \%$ of the votes. However, one should note that voters' absenteeism was about $40 \%$ and that Angola was experiencing social protests against the regime, inspired by the Arab Spring. 
The Angolan education system has been highly dualised since the early 1990s. In fact, the adoption of a market economy allowed for the transformation of education into a new arena of capitalist investment and exploitation. A large number of private schools, national and foreign, were created. Many of them have as stakeholders members of the political and economic elite. The fees demanded are impossible for the vast majority of the population to pay. And this rift is racially manifested. This leads clearly to a reproduction of severe social inequalities that affect most of the black population. Meanwhile, public schools are underfunded and deprived of basic conditions (power, water, classrooms), and teachers present grave deficiencies in their academic preparation and pedagogical practices. Their very low salaries also force them to invest in other sources of income. Hence, teacher absenteeism is a huge challenge.

A similar portrait emerges in the Angolan higher education system. Besides public universities in Angolan provinces, there are many private institutions. Again, these are owned by members of the political and economic elite and by enterprises and companies. Popular degrees are in law, economics, engineering, marketing, business, administration, and so forth. Weak as they are, these institutions are attended mostly by the children of the former emergent middle class, who have no choice. Highranking elites seek out foreign universities in Europe, Brazil, the USA and Russia.

Agostinho Neto University is a public university initially created by the Portuguese around 1962 at a moment when the anti-colonial liberation struggle was spreading throughout the territory. Being a public institution, students that attend classes during the morning and afternoon periods don't have to pay any fees. A vast majority of the students come from low- and very low-income black families with poor educational backgrounds and poor access to essential requirements such as reading material and internet access. This means that the costs associated with attending classes (transportation, food, materials) remain too high for most. A significant number of students have to work at formal and informal jobs to make ends meet and to contribute to the family's income. Some only eat in the evening when they return home. With the current crisis, many are leaving school. The majority of the students have gone through the public education system, which is still quite frail in terms of access and quality. Thus, these students experience a number of difficulties related to literacy. ${ }^{37}$

Similar to many other contexts (and not only African), the public higher education system is currently being confronted with global demands in terms of marketoriented policies while still being conceived as a disciplinary instrument of political conformity. In this sense, the Angolan public university presents itself as an eloquent case study of the alliance between a neoliberal outlook on education and contemporary forms of state nationalism.

37 Most of them only read in Portuguese and experience varying degrees of difficulty in doing so. Also, most students and teachers do not know any other national language - and even if they did, there are no materials in those languages. 


\section{Disciplinary education}

Given the transformations of our global knowledge economy, the discourse that gains the forefront is that which conceptually agglutinates education, employability, citizenship and development. What, in fact, is needed? New docile sociopolitical subjectivities, preferably with a wide range of skills, mainly technical, endowed with a flexible and adaptable spirit to face markets' fluctuations and evolution. Why is this needed? Two forces seem to be at work: on the one hand, neoliberal globalisation's pressures; on the other, a national political economy whereby development choices continue to be anchored on the dynamics of private capital accumulation and an authoritarian culture. Concerning curricula, Francis B. Nyamnjoh aptly described the overall situation, arguing that the 'educational system is too standardized, uniformized, technicized, depoliticized and detached to be in tune with the predicaments of ordinary and marginal Africans thirsty and hungry for recognition, representation and upliftment. ${ }^{38}$

There is thus a normative view of education as a means for employability or, perhaps even better, market success, and a decreasing focus on its emancipatory and empowering character. Concerning students, one witnesses the increasingly naturalised idea that education is primarily aimed to assure market success. Naturally, this concerns the legitimate aspirations of those who would improve their life conditions. In this sense, and in certain circumstances, inequality and poverty can become a useful pool for reproducing a neoliberal framework for education.

One can also address these issues by considering the degree to which humanities and academic research is increasingly dependent on consultancy contracts with private enterprises, international donors and development and/or governmental agencies. Currently, there are no public funds for research in humanities. Most research centres of the public university are either phantom structures or consultancy offices. In an authoritarian culture, consultancy and research are subject to conformity. Technical knowledge is preferred. Socially engaged knowledge is not to be too politicised. Many are the consequences in terms of critical thinking, freedom and the ability to act. In fact, can a technocratic outlook on knowledge provide an understanding of the experiential nature of existence? Does it allow for any kind of empathetic resonance that fosters a sense of mutual belonging and shared vulnerability? ${ }^{39}$

\section{State nationalism and identity politics}

When focusing on the historical trajectory of Arabic universities, Edward Said reflects upon the implications of conceiving universities as both political and nationalist

38 Francis B. Nyamnjoh, “Potted Plants in Greenhouses": A Critical Reflection on the Resilience of Colonial Education in Africa', Journal of Asian and African Studies, 47(2) (2012), 15. doi: 10.1177/0021909611417240.

39 In this paper, the use of the notion of empathy distances itself from what could be called a colonial epistemology of possession. In fact, critics have noticed the narcissistic stance of empathy as that which allows the incorporation/normalisation and possession of the other. In this sense, empathy has a predatory character. This is an important criticism to unveil empathy's aporias. However, empathy can also be pursued outside the colonial epistemology of possession and understood and practised not as a self-attesting dynamic, but as a transcendental aspiration. 
institutions. This conceptualisation is completely understandable given the history of these societies. Similar to African experiences, Arabic countries' independence often meant the 'Arabisation' of the curriculum. Said points out, however, that after independence, some universities experienced pressure towards political conformity, which led to 'a studious lack of imagination, and careful conservatism' as the rule of 'intellectual practice'. In those cases, 'nationalism in the university has come to represent not freedom but accommodation, not brilliance and daring but caution and fear, not the advancement of knowledge but self-preservation. ${ }^{40}$

This emptying of emancipatory possibilities in education and the role of the university has been the result of how the prevalence of undemocratic rule transformed what liberation struggles set out to do into normative and disciplinary politics. Similar processes can be traced in the Angolan experience. One crude manifestation is how debates on knowledge coloniality are locally articulated.

Overall, one notices either an absence of debates on coloniality or a quite superficial engagement in the critique of knowledge. When the coloniality debate is absent, prevailing discourses emphasise Angola's modernity and its integration in the world and regional systems as an emerging power. In these discourses, the country's fulfilment coincides with modernity's promises and current globalisation models. Hence, a debate on coloniality loses significance. On the other hand, those same discourses coexist with celebration of the Angolan exceptionality. Promoted by forms of state nationalism, the Angolan exceptionality (as well as others' exceptionalities) in the course of its liberation and postcolonial development is politically articulated as the fulfilment of an identity politics constructed around the notion of angolanidade. This notion frames citizenship and also politics of recognition and operates as a decolonising standpoint which contributes to coloniality's invisibility. Why? Because if one is truly Angolan, one is already free and thus decolonised. When present, the debate on the prevalence of Eurocentrism and the need to decolonise tends to be reduced to an 'identity politics' through which essentialists readings become popularised. And once again, the discourse on angolanidade is activated. Thus, the notion of angolanidade is reduced to two apparently opposed essentialisms that are manipulated according to contexts and demands: an essentialism that highlights the purity of cultural heritage and an essentialism that stresses the natural distinctiveness, exceptionality and modernity of national character.

Any debate on coloniality is to be developed along three axes: coloniality of power, of knowledge and of being. The interrogations that these axes allow directly challenge power structures. They pose questions concerning what power is, and how it is organised and exercised. They pose questions relating to who produces knowledge, with what, for what, and its consequences. And they pose questions regarding identity politics and express the will to go beyond imposed limits on our understanding of ourselves and others. In this sense, the degree to which these interrogations are freely 
articulated is a measure of a critical reflexivity that can only flourish within broader democratic developments.

An academic life that acritically celebrates such narratives of cultural identity and status quo, while producing perennial hostility towards others, will hardly experience freedom. Sen criticises this stance as it forecloses any act of freedom and conscious choice about identity matters and condemns people to a persistent dilemma between alienation and authenticity and to a simplistic reading of historical experiences. ${ }^{41}$ In fact, most critiques focus on the negative effects of seeing the other as a stereotype. However, a more comprehensive critique will show that such a culturalist and exclusionary view of identity not only produces stereotypes in our perception of others, but also in our perception of ourselves. This corresponds to a miniaturisation of the human spirit that simultaneously objectifies the other and reduces the self to a pregiven set of conceptualisations about identity, dramatically diminishing the ability to exercise freedom, reasoning, critical thinking and conscious choice. Miniaturisation of the human spirit is a reification gesture of the other and of the self. Within this framework, one is deprived of the necessary resources to experience oneself beyond one's own limits, remaining trapped and not understanding that identity is on the move as a grounded and hermeneutical projection of transcendence. As Said explains:

Rather than viewing the search for knowledge in the academy as the search for coercion and control over others we should regard knowledge as something for which to risk identity and we should think of academic freedom as an invitation to give up on identity in the hope of understanding and perhaps even assuming more than one. ${ }^{42}$

An outdated concept of identity insists on essentialist yearnings that falsify critical thought. Identities are open-ended and should be assumed as ethically oriented constructions. And as constructions, they are dynamic and if they are dynamic they have in themselves the possibility of transcendence. If this basic reasoning about identity can be inserted into educational systems, then one might encounter afresh the role of education and the university: transcendence towards and through knowledge, understanding, justice, freedom and the advancement of the existential conditions of human and non-human life.

It is a role that is thus politicised but not closed up in partial and hegemonic senses of identity. It is independent because it is not restricted to a pre-given set of premises and goals. It is also hermeneutically grounded because that represents the condition of validity without being parochial and essentialist. On the contrary, it is cosmopolitan, because it amplifies our opportunities for transcendence through interconnectedness while protecting us against any type of reduction - either coming from imperialistic impulses, or from local essentialist canons. 


\section{Thoughtlessness}

In the context of an authoritarian culture, an ingrained habit of non-questioning of authority tends to prevail. Obviously, this is not a natural disposition, but a learned attitude. Regarding the pedagogical relationship between teacher and student, for example, there is a common practice of rejecting students' interpretations and readings because students are seen as being ill equipped to offer them. Rather, what is commonly requested from students is a sort of recitation. Reflexivity is dislocated for the individual's private sphere and inner abilities, thus losing its cathartic power. It is also common fact that most students are not used to writing in their own words. This phenomenon cannot be understood as being solely a matter of plagiarism. It is also the result of disseminated educational practices leading to a form of thought mimicry and a knowledge simulacrum whereby no knowledge appropriation or questioning can be properly developed and students cannot assert themselves as knowledge producers. Recovering a popular linguistic expression from the Marxist-Leninist period, they are chains of transmission.

Critical thought is discouraged, but so too is critical pedagogy, seen as 'social activism' and a transgression of the rigour of science. Arguments about neutrality and objectivity are evoked once again and pave the way for a depoliticised knowledge, even if socially engaged. This is understandable since critical pedagogy is 'a moral and political practice that always presupposes particular renditions of what represents legitimate knowledge, values, citizenship, modes of understanding and views of the future.43 And, to evoke Said once again: 'To make the practice of intellectual discourse dependent on conformity to a predetermined political ideology is to nullify intellect altogether. ${ }^{34}$

Hannah Arendt speaks of thoughtlessness, or a fundamental inability to think, as one basic element of any totalitarian experience and of ideological extremism. Again: in global trends such as those described above, thoughtlessness is not an individual deficiency or a cultural disposition; it is becoming an actively produced cognitive structure. Against this, Arendt proposes a practice of thinking as an interruption of oneness, freeing one to the actuality of others and otherness. ${ }^{45}$ In the European hermeneutical tradition, Hans-Georg Gadamer defined understanding as freedom of spirit. ${ }^{46}$ In Rabindranath Tagore's Indian educational practice, freedom is understood as the ability to produce our own thoughts. ${ }^{47}$ In African philosophy, Fabien Eboussi Boulaga argued that philosophy transforms itself into an emancipatory praxis when an individual critically and systematically constructs a discourse for him/herself. ${ }^{48}$

A.H. Giroux and S.S. Giroux, 'Challenging Neoliberalism's New World Order: The Promise of Critical Pedagogy', Cultural Studies, Critical Methodologies, 6(1) (2006), 28.

44 Said, Reflections on Exile, 393.

45 Mark Antaki, 'What Does It Mean to Think about Politics?' in Roger Berkowitz, Jeffrey Katz and Thomas Keenan, eds., Thinking in Dark Times: Hannah Arendt on Ethics and Politics (New York: Fordham University Press, 2010), 63-69.

46 Hans-Georg Gadamer, Philosophical Hermeneutics, translated and edited by David E. Linge (Berkeley, CA: University of California Press, 1997).

47 Cf. Fakrul Alam and Radha Chakravarty, eds., The Essential Tagore (London: The Belknap Press of Harvard University Press, 2011).

48 Fabien Eboussi Boulaga, Muntu in Crisis: African Authenticity and Philosophy (Trenton, NJ: Africa World Press, 2014). 
That is probably the reason why Ernest Wamba-dia-Wamba argues for a philosophy that can become 'a socialized practice ${ }^{249}$ and also why Jean-Marc Ela emphasises how African philosophy, in particular, should contribute to a new knowledge theory away from market-oriented dispositions..$^{50}$

Given its relationship with the experience and the exercise of freedom, critical thinking cannot but manifest itself in politics. It is a relentless quest for meaning which can never be crystallised and which dissolves and examines anew all that has been accepted. In existentialist terms, it allows for the experience of nothingness and thus of freedom.

\section{Conclusion, or the refusal to tyrannise}

Hannah Arendt formulated another concept which seems to be quite pertinent today. She speaks of a lying world order. The concept does not refer simply to a basic falsehood which can be defined as the victory of an argument at the expense of truth. For Arendt, a lying world order is one based on the victory of an argument at the expense of reality itself. ${ }^{51}$ In order to avoid its traps, factual truths, she argues, play a fundamental role. These relate to social life and collective and individual experiences and are thus contingent. However, their potential to dismantle any lying world order resides in witness and testimony and their irreducible visibility. It also resides in the ability to cultivate the heretic nature of critical thinking.

And what is critical thinking? Sustained by intellectual freedom, critical thinking might be best understood and practised as the condition for the avoidance of coercive normalisation. It is the tool through which individuals can sustain democratic control over institutions, societies and destinies or futures. Critical thinking might also be better understood as the systematised and demanding attitude of transcendence. This is what is conveyed by the notion of critical ontology formulated by Foucault. ${ }^{52}$ A critical ontology is therefore the subtext of humanities' criticism; a horizon opened up by humanities' second-order observation. Indeed, its being-in-the-world should correspond to an expansion of horizons of possibility, anchored cross-learning processes, which are not enforced but simply available as repositories and resources of meaning-construction processes that can sustain us into the future. Or as Boulaga explained, critical thinking consists in the activity of a consciousness seeking to understand itself and its reality in order to critically actualise itself for itself. ${ }^{53}$

The challenges for the contemporary university are multiple and complex and affect especially the African university. Indeed, given its specific historical circumstances, as Ela argued, the African university needs to make foundational choices.

49 Ernest Wamba-dia-Wamba, 'Philosophy in Africa: Challenges of the African Philosopher' in T. Serequeberhan, ed., African Philosophy: Essential Readings (New York: Paragon House, 1991), 232.

50 Ela, Investigação científica.

51 P. Birmingham, 'A Lying World Order: Political Deception and the Threat of Totalitarianism' in Roger Berkowitz, Jeffrey Katz and Thomas Keenan, eds., Thinking in Dark Times: Hannah Arendt on Ethics and Politics (New York: Fordham University Press, 2010), 73-77.

52 Michel Foucault, Ethics: Essential Works of Michel Foucault 1954-1984 (London: New Press, 1997).

53 Boulaga, Muntu in Crisis. 
Nevertheless, any university in our days should address what Jean-Marc Ela calls a rationality crisis. That endeavour should certainly include humanities' questioning, a new commitment to intellectual and academic freedom and, last but not least, a new global conversation on the knowledge political economy and on the urgency for a cosmopolitan citizenry.

Once I was running late and my mother asked me when I got home:

'It took you a while to get here. Did you meet someone along the way?'

'No mom, I didn't.'

Throwing me into a speechless void, she quickly replied:

'Then what is the world good for?'54 